\title{
A New Global Mechanism for MILD Combustion Using Artificial-Neural-Network-based Optimization
}

\author{
Jicang $\mathrm{Si}^{\text {a }}$, Guochang Wang a,b, Xiangtao Liu a, Mengwei $\mathrm{Wu}^{\text {a }}$, Jianchun Mi a,b* \\ ${ }^{a}$ College of Engineering, Peking University, Beijing 100871, P.R. China \\ ${ }^{\mathrm{b}}$ Marine Engineering College, Dalian Maritime University, Dalian 116026, P.R. China \\ *Correspondence to: jmi@pku.edu.cn (J. Mi)
}

\section{Section 1. Reaction parameters of other possible combinations of Westbrook \&}

\section{Dryer $^{1}$ and Jones \& Lindestedt ${ }^{2}(\mathrm{JL})$ mechanisms}

Chemical reactions in the WD mechanism are the following R1-R3:

$$
\begin{aligned}
& \text { (R1) } \mathrm{CH}_{4}+0.5 \mathrm{O}_{2} \rightarrow \mathrm{CO}+\mathrm{H}_{2} \mathrm{O} \\
& \text { (R2) } \mathrm{CO}+0.5 \mathrm{O}_{2} \leftrightarrow \mathrm{CO}_{2} \\
& \text { (R3) } \mathrm{H}_{2}+0.5 \mathrm{O}_{2} \leftrightarrow \mathrm{H}_{2} \mathrm{O}
\end{aligned}
$$

while those for the JL mechanism are R3-R6:

$$
\begin{gathered}
\text { (R4) } \mathrm{CH}_{4}+0.5 \mathrm{O}_{2} \rightarrow \mathrm{CO}+\mathrm{H}_{2} \\
\text { (R5) } \mathrm{CH}_{4}+\mathrm{H}_{2} \mathrm{O} \rightarrow \mathrm{CO}+3 \mathrm{H}_{2} \\
\text { (R6) } \mathrm{CO}+\mathrm{H}_{2} \mathrm{O} \leftrightarrow \mathrm{CO}_{2}+\mathrm{H}_{2} \\
\text { (R3) } \mathrm{H}_{2}+0.5 \mathrm{O}_{2} \leftrightarrow \mathrm{H}_{2} \mathrm{O}
\end{gathered}
$$

Here, for the intermediate generation of $\mathrm{H}_{2}, \mathrm{R} 1$ is not considered to combine new global mechanism. Therefore, there are 7 possible combinations for a new global mechanism: i.e., (R2, R3, R4, R5, R6), (R2, R3, R4, R6) (the same as the GM mechanism in the previous work), (R2, R3, R5, R6), (R2, R3, R4), (R2, R3, R5), (R3, R4, R6) and (R3, R5, R6). Their parameters are all optimized with the same ANN method to GM-ANN. Respectively, we named these refined mechanisms as 5-step-ANN, GMANN2, 4-step-ANN, 3-step1-ANN, 3-step2-ANN, 3-step3-ANN and 3-step4-ANN. Note that GMANN2 is different from GM-ANN in the reaction order of R2 and R4. Only the reaction order of R2 
and R4 in GM-ANN differs from that in the WD or JL mechanism.

Table S1. Reaction parameters of different combination of JL and WD mechanisms

\begin{tabular}{|c|c|c|c|c|c|}
\hline Mechanism & Reaction & $A\left(\left(\mathrm{~cm}^{3} / \mathrm{mol}\right)^{\mathrm{n}-1} / \mathrm{s}\right)$ & $b$ & $E_{\mathrm{a}}(\mathrm{cal} / \mathrm{mol})$ & Reaction Order \\
\hline \multirow[t]{5}{*}{ 5-step-ANN } & R4 & $3.85 \times 10^{12}$ & 0.21 & 28841 & {$\left[\mathrm{CH}_{4}\right]^{0.5}\left[\mathrm{O}_{2}\right]^{1.25}$} \\
\hline & R5 & $3.00 \times 10^{11}$ & -0.13 & 26535 & {$\left[\mathrm{CH}_{4}\right]\left[\mathrm{H}_{2} \mathrm{O}\right]$} \\
\hline & R6 & $8.32 \times 10^{10}$ & 0.21 & 22012 & {$[\mathrm{CO}]\left[\mathrm{H}_{2} \mathrm{O}\right]$} \\
\hline & $\mathrm{R} 2$ & $3.55 \times 10^{11}$ & 0.22 & 39152 & {$[\mathrm{CO}]\left[\mathrm{O}_{2}\right]^{0.25}\left[\mathrm{H}_{2} \mathrm{O}\right]^{0.5}$} \\
\hline & R3 & $1.62 \times 10^{11}$ & -0.16 & 20395 & {$\left[\mathrm{H}_{2}\right]\left[\mathrm{O}_{2}\right]^{0.5}$} \\
\hline \multirow[t]{4}{*}{ GM-ANN2 } & $\mathrm{R} 4$ & $5.41 \times 10^{11}$ & 0.08 & 20364 & {$\left[\mathrm{CH}_{4}\right]^{0.5}\left[\mathrm{O}_{2}\right]^{1.25}$} \\
\hline & R6 & $5.47 \times 10^{10}$ & -0.02 & 23664 & {$[\mathrm{CO}]\left[\mathrm{H}_{2} \mathrm{O}\right]$} \\
\hline & $\mathrm{R} 2$ & $6.41 \times 10^{8}$ & -0.10 & 34159 & {$[\mathrm{CO}]\left[\mathrm{O}_{2}\right]^{0.25}\left[\mathrm{H}_{2} \mathrm{O}\right]^{0.5}$} \\
\hline & $\mathrm{R} 3$ & $2.45 \times 10^{11}$ & 0.14 & 31938 & {$\left[\mathrm{H}_{2}\right]\left[\mathrm{O}_{2}\right]^{0.5}$} \\
\hline \multirow[t]{4}{*}{ 4-step-ANN } & R5 & $5.92 \times 10^{12}$ & -0.06 & 16950 & {$\left[\mathrm{CH}_{4}\right]\left[\mathrm{H}_{2} \mathrm{O}\right]$} \\
\hline & R6 & $5.25 \times 10^{12}$ & -0.05 & 34118 & {$[\mathrm{CO}]\left[\mathrm{H}_{2} \mathrm{O}\right]$} \\
\hline & $\mathrm{R} 2$ & $7.94 \times 10^{11}$ & 0.02 & 32323 & {$[\mathrm{CO}]\left[\mathrm{O}_{2}\right]^{0.25}\left[\mathrm{H}_{2} \mathrm{O}\right]^{0.5}$} \\
\hline & R3 & $1.35 \times 10^{12}$ & -0.17 & 35573 & {$\left[\mathrm{H}_{2}\right]\left[\mathrm{O}_{2}\right]^{0.5}$} \\
\hline \multirow[t]{3}{*}{ 3-step-ANN1 } & R4 & $6.54 \times 10^{11}$ & 0.23 & 20850 & {$\left[\mathrm{CH}_{4}\right]^{0.5}\left[\mathrm{O}_{2}\right]^{1.25}$} \\
\hline & R2 & $1.85 \times 10^{11}$ & 0.16 & 35462 & {$[\mathrm{CO}]\left[\mathrm{O}_{2}\right]^{0.25}\left[\mathrm{H}_{2} \mathrm{O}\right]^{0.5}$} \\
\hline & R3 & $5.03 \times 10^{11}$ & 0.00 & 23401 & {$\left[\mathrm{H}_{2}\right]\left[\mathrm{O}_{2}\right]^{0.5}$} \\
\hline \multirow[t]{3}{*}{ 3-step-ANN2 } & R5 & $1.92 \times 10^{12}$ & 0.13 & 25272 & {$\left[\mathrm{CH}_{4}\right]\left[\mathrm{H}_{2} \mathrm{O}\right]$} \\
\hline & R2 & $4.96 \times 10^{12}$ & -0.14 & 38894 & {$[\mathrm{CO}]\left[\mathrm{O}_{2}\right]^{0.25}\left[\mathrm{H}_{2} \mathrm{O}\right]^{0.5}$} \\
\hline & R3 & $3.42 \times 10^{12}$ & -0.12 & 28355 & {$\left[\mathrm{H}_{2}\right]\left[\mathrm{O}_{2}\right]^{0.5}$} \\
\hline \multirow[t]{3}{*}{ 3-step-ANN3 } & R4 & $8.35 \times 10^{10}$ & 0.14 & 22580 & {$\left[\mathrm{CH}_{4}\right]^{0.5}\left[\mathrm{O}_{2}\right]^{1.25}$} \\
\hline & R6 & $5.88 \times 10^{12}$ & -0.05 & 31243 & {$[\mathrm{CO}]\left[\mathrm{H}_{2} \mathrm{O}\right]$} \\
\hline & R3 & $5.64 \times 10^{11}$ & 0.02 & 36231 & {$\left[\mathrm{H}_{2}\right]\left[\mathrm{O}_{2}\right]^{0.5}$} \\
\hline \multirow[t]{4}{*}{ 3-step-ANN4 } & R5 & $8.64 \times 10^{12}$ & 0.09 & 22407 & {$\left[\mathrm{CH}_{4}\right]\left[\mathrm{H}_{2} \mathrm{O}\right]$} \\
\hline & R6 & $5.88 \times 10^{12}$ & -0.05 & 31243 & {$[\mathrm{CO}]\left[\mathrm{H}_{2} \mathrm{O}\right]$} \\
\hline & R6 & $9.23 \times 10^{11}$ & 0.07 & 27124 & {$[\mathrm{CO}]\left[\mathrm{H}_{2} \mathrm{O}\right]$} \\
\hline & R3 & $3.36 \times 10^{12}$ & -0.09 & 33414 & {$\left[\mathrm{H}_{2}\right]\left[\mathrm{O}_{2}\right]^{0.5}$} \\
\hline
\end{tabular}

Section 2. Comparison of GM-ANN and other possible combinations of JL and WD mechanisms in PSR, JHC and in-furnace MILD combustions 


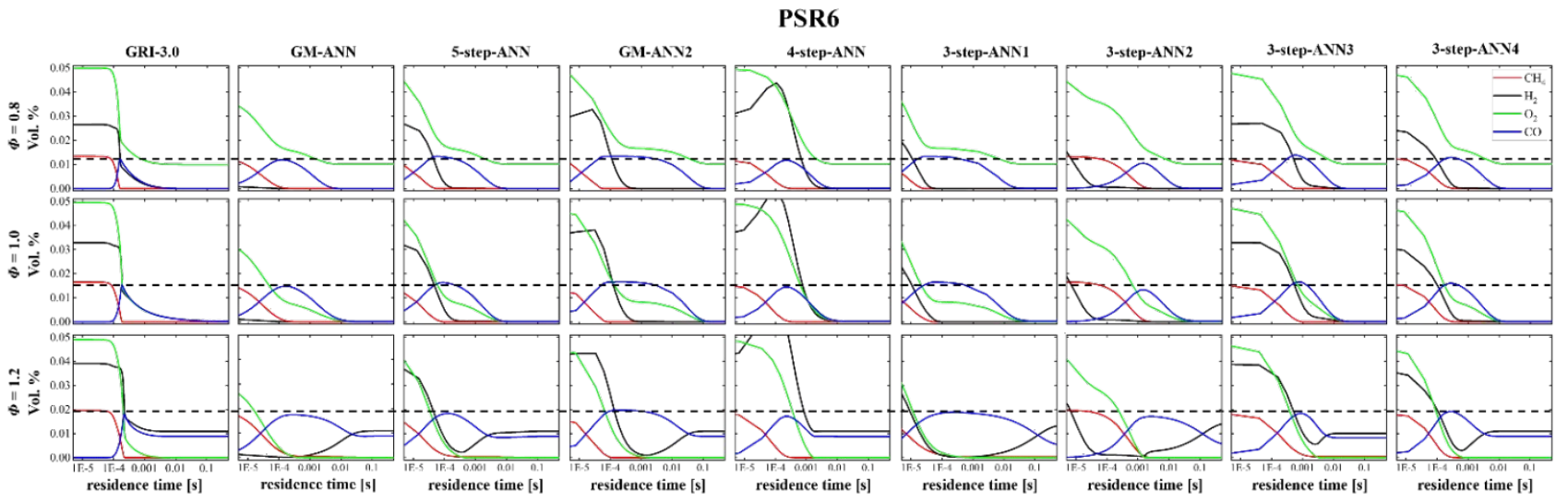

Figure S1. Comparisons of $\mathrm{CH}_{4}, \mathrm{H}_{2}, \mathrm{O}_{2}$ and $\mathrm{CO}$ concentration in PSR6 versus residence time in PSR6 between combination of JL and WD mechanisms, GM-ANN and GRI-3.0 at $T_{\mathrm{PFR}}=1600 \mathrm{~K}$ and $\Phi=0.8,1.0 \& 1.2$.

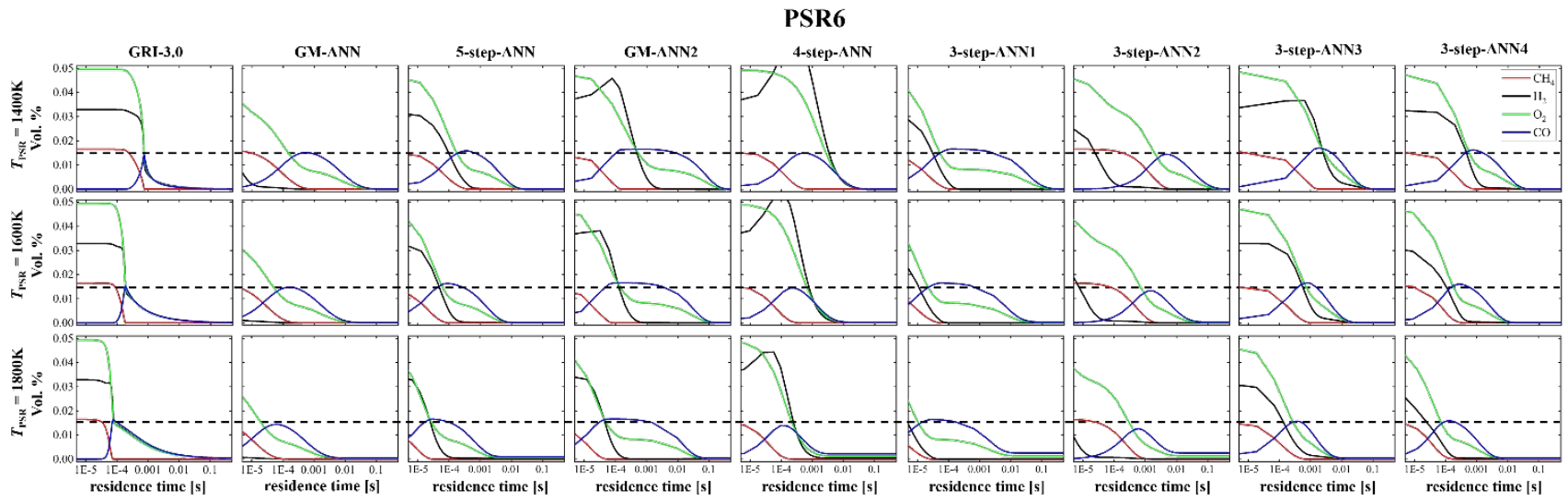

Figure S2. Comparisons of $\mathrm{CH}_{4}, \mathrm{H}_{2}, \mathrm{O}_{2}$ and $\mathrm{CO}$ concentration versus residence time in PSR6 between combination of JL and WD mechanisms, GM-ANN and GRI-3.0 at $\Phi=1.0$ and $T_{\mathrm{PSR}}=$ $1400,1600 \& 1800 \mathrm{~K}$. 


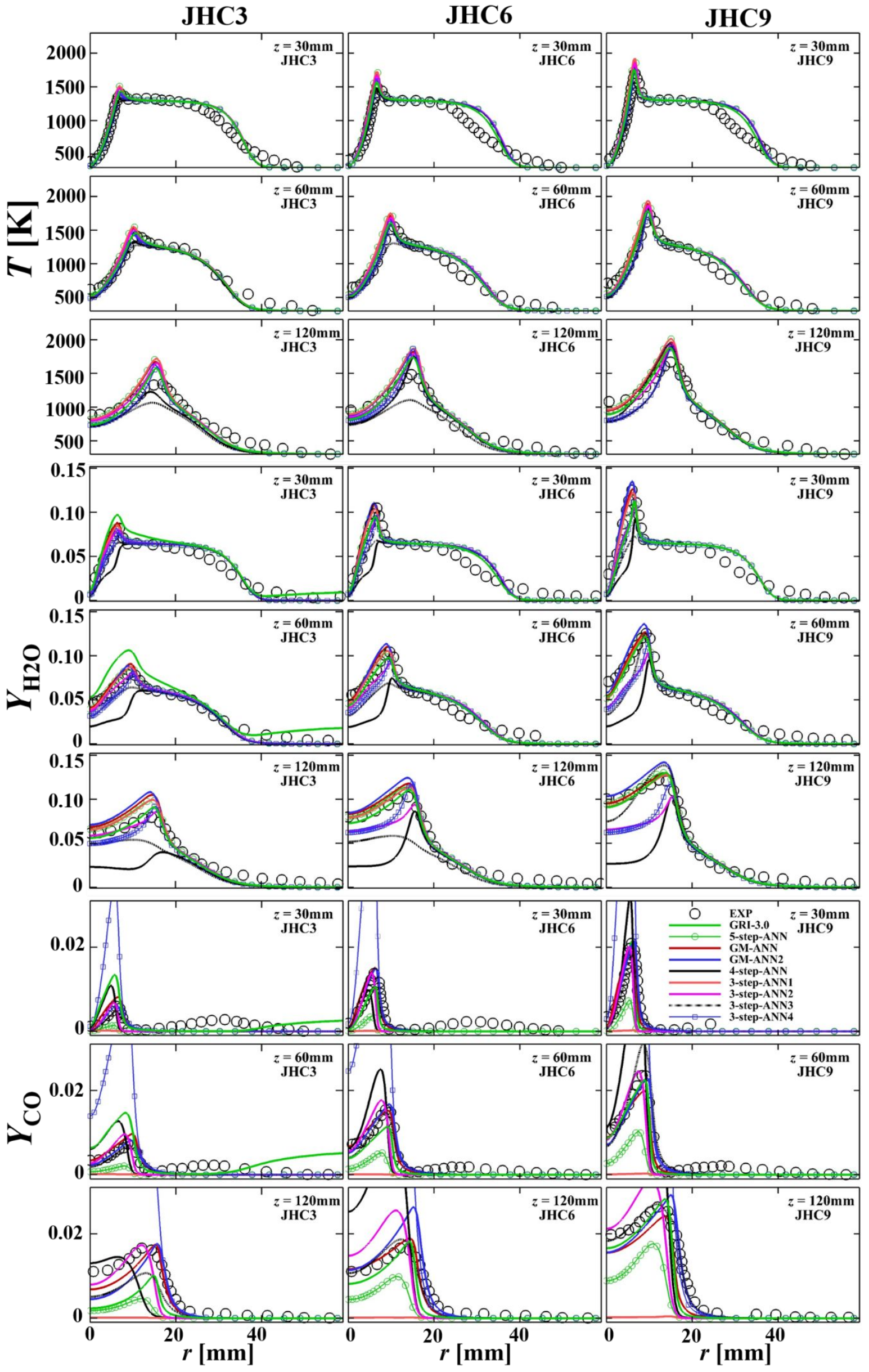


Figure S3. Distributions of the mean temperature $(T)$, mass fractions of $\mathrm{H}_{2} \mathrm{O}\left(Y_{\mathrm{H} 2 \mathrm{O}}\right)$ and $\mathrm{CO}\left(Y_{\mathrm{CO}}\right)$ of the JHC flame of burning methane/hydrogen versus radial distance $r$, obtained by CFD simulations using different mechanisms (combination of JL and WD mechanisms, GM-ANN and GRI-3.0) and experimentally by Dally et al. ${ }^{3}$ (circle) under JHC3, JHC6 and JHC9 conditions.

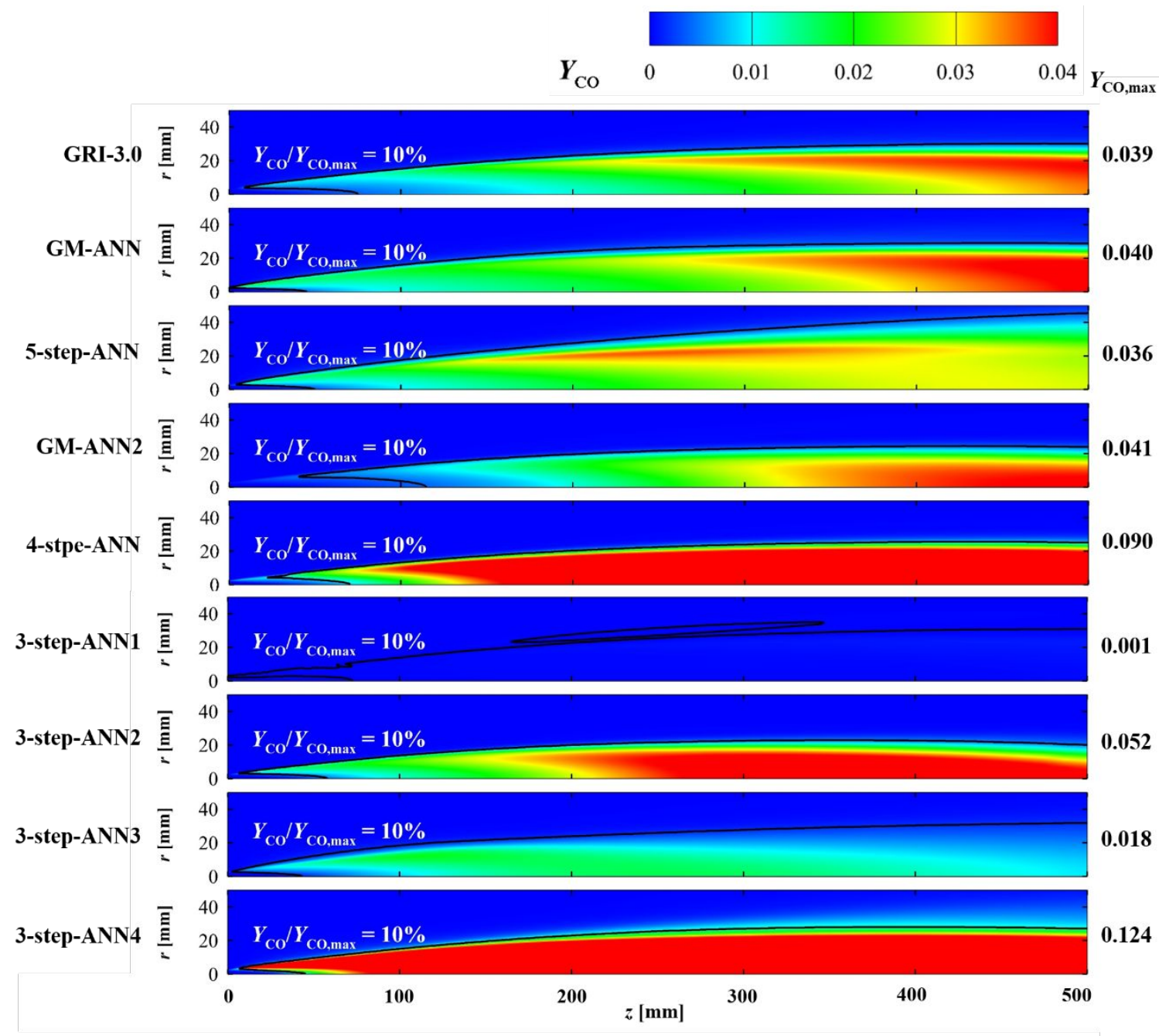

Figure S4. Planar distributions of the $\mathrm{CO}$ mass fraction $\left(\mathrm{Y}_{\mathrm{CO}}\right)$ of the $\mathrm{CH}_{4} / \mathrm{H}_{2} \mathrm{JHC}$ flame calculated through different mechanisms. Solid lines represent the contours of $\mathrm{Y}_{\mathrm{CO}} / \mathrm{Y}_{\mathrm{CO} \text {, max }}=10 \%$, respectively. 

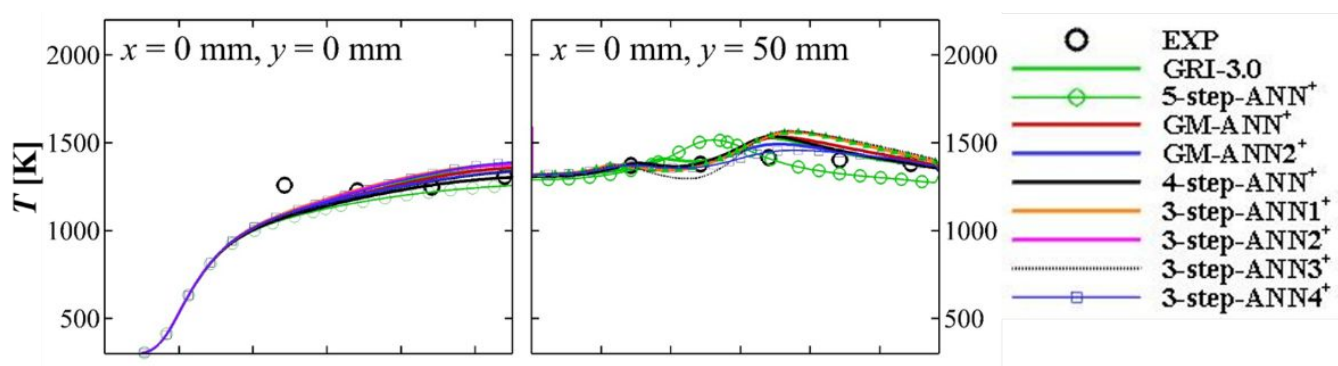

(a)

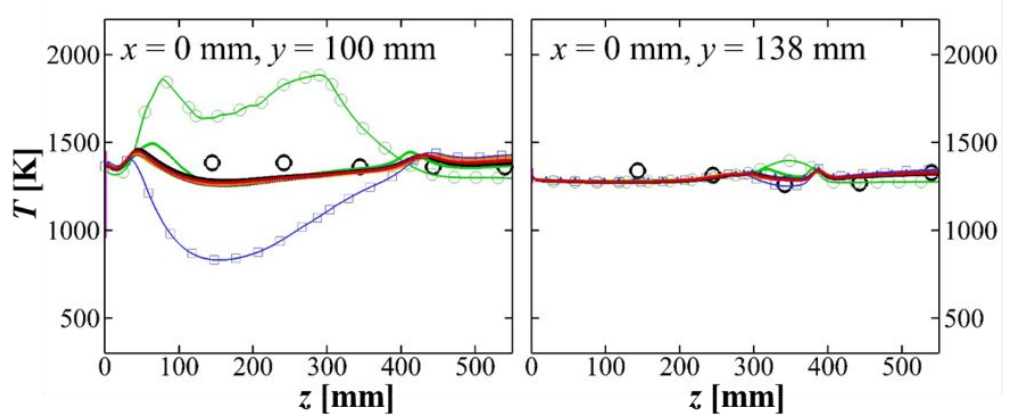

(b)
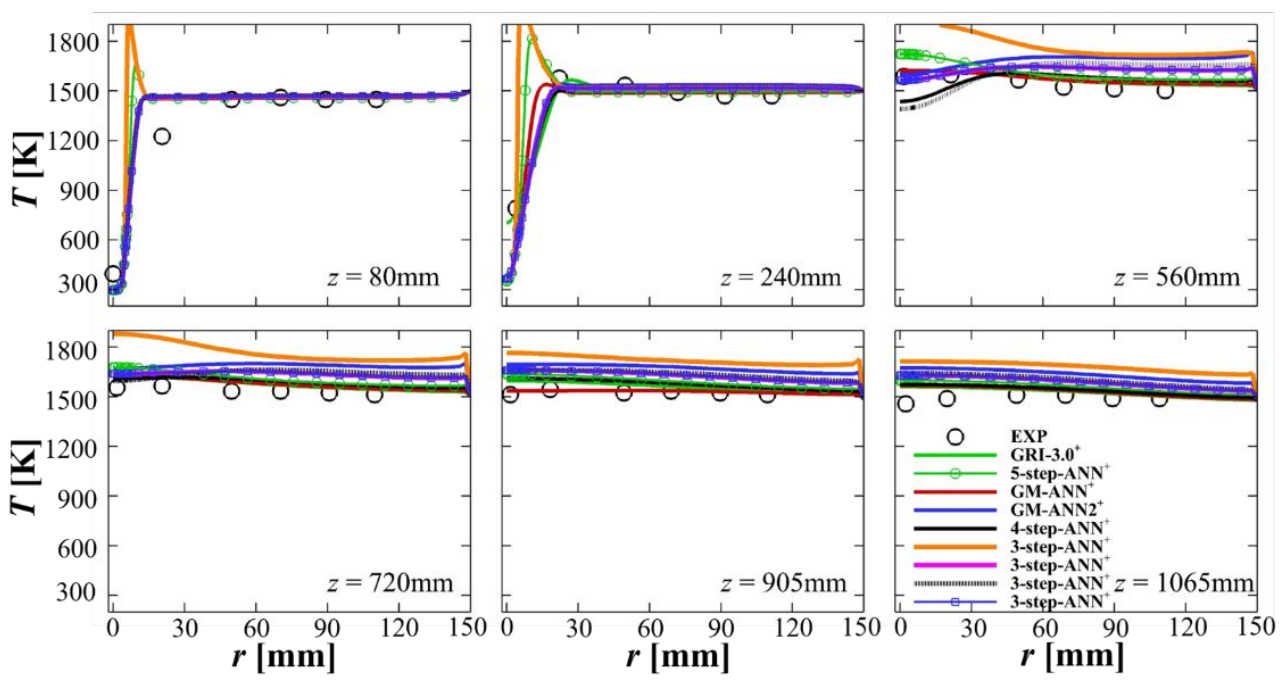

Figure S5. Comparison of different global mechanisms with the detailed mechanism and experimental data for temperature distributions $(T)$ of the in-furnace MILD combustion. (a) Nonpremixed case ${ }^{4}$; (b) premixed case ${ }^{5}$. 


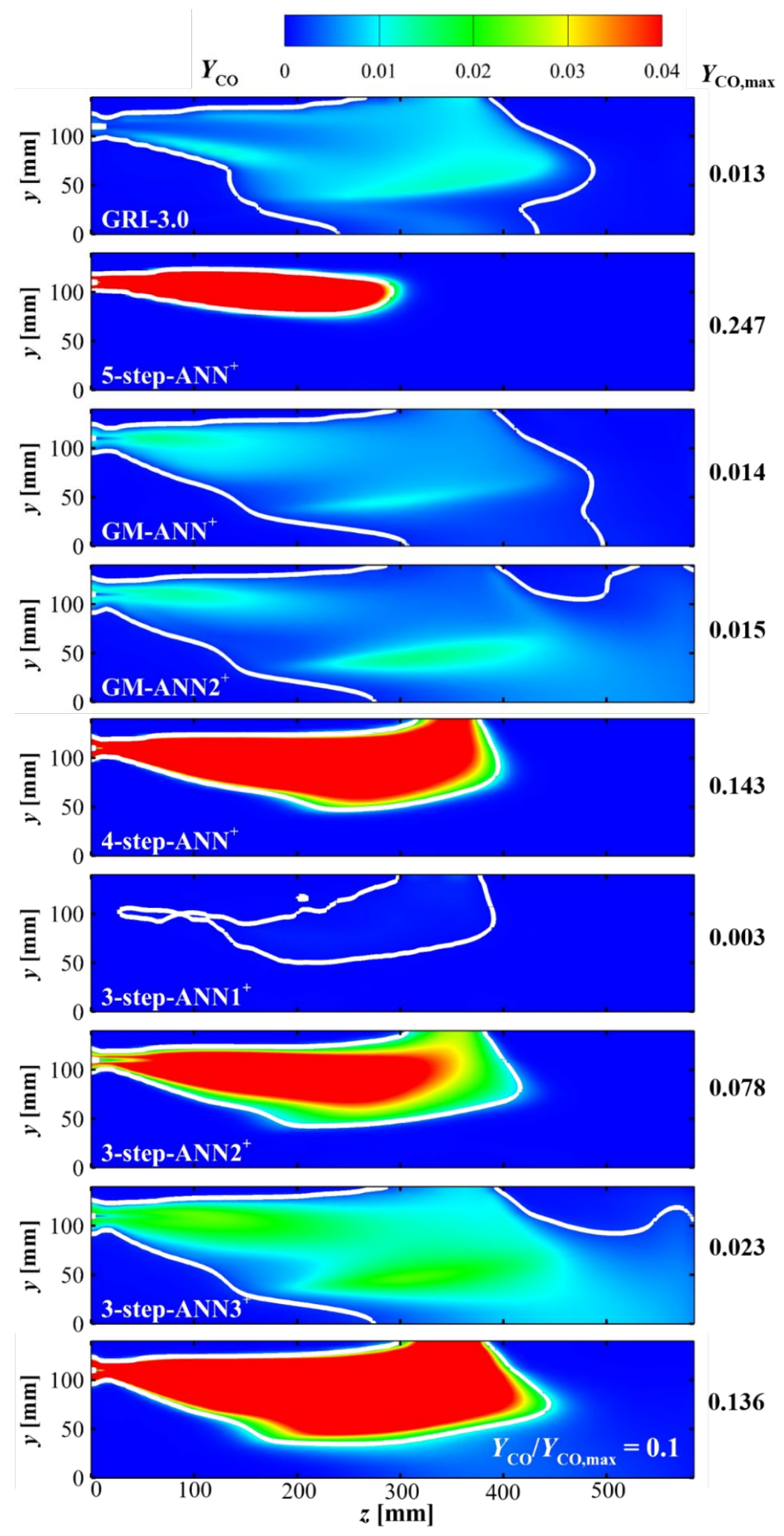

Figure S6. Planar distributions of the $\mathrm{CO}$ mass fraction $\left(Y_{\mathrm{CO}}\right)$ for the simulated furnace MILD combustion $^{4}$ obtained using GRI-3.0, GM-ANN+ and different global mechanisms by combination of WD and JL mechanisms. White solid lines are the contours of $Y_{\mathrm{CO}} / Y_{\mathrm{CO}, \max }=0.1$. 


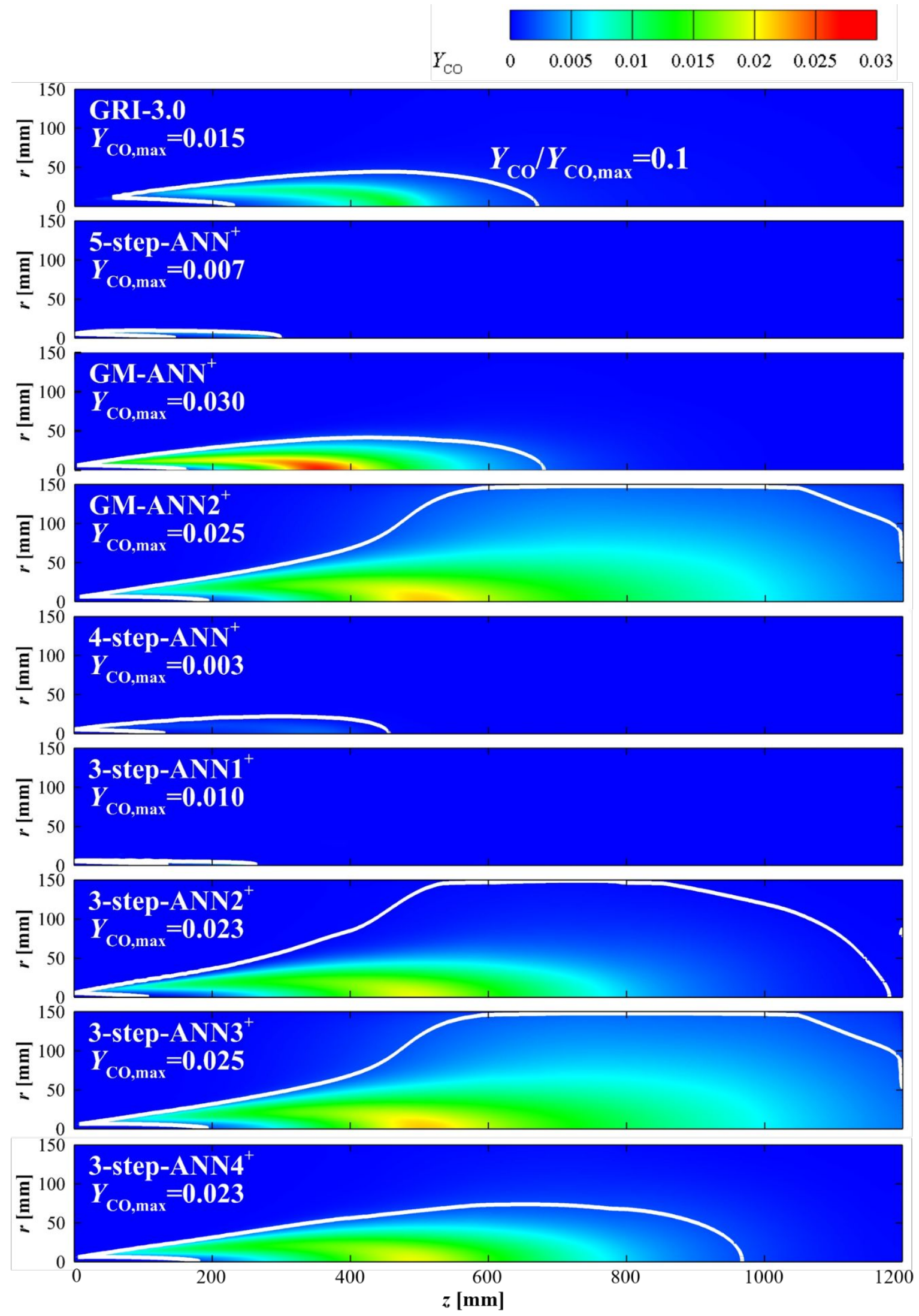

Figure S7. Planar distributions of the CO mass fraction $\left(Y_{\mathrm{CO}}\right)$ in the premixed MILD combustion furnace $^{5}$ calculated through GRI-3.0, GM-ANN+ and different global mechanisms by combination of WD and JL mechanisms. White solid lines are the contours of $Y_{\mathrm{CO}} / Y_{\mathrm{CO}, \max }=0.1$. 
Figures S1-S6 show the performance of GM-ANN and other different combinations of WD and JL mechanisms in JHC flame ${ }^{3}$, non-premixed MILD combustion furnace ${ }^{4}$ and premixed MILD combustion furnace ${ }^{5}$. Results show that GM-ANN2 performs overall the best on CO prediction among other combinations of WD and JL mechanisms for CFD simulation. Therefore, reactions in GM-ANN2 (and GM-ANN) is the most suitable. However, the result between GM-ANN and GMANN2 shows that GM-ANN is better than GM-ANN2. Specifically, GM-ANN2 underestimates the consumption rate of $\mathrm{CO}$, especially for premixed furnace combustion ${ }^{5}$. This is due to the difference in reaction order for R2 and $\mathrm{R} 4$. Therefore, it might be necessary to re-optimize the reaction order of the global mechanism in different combustion conditions.

\section{References}

(1) Westbrook, C. K.; Dryer, F. L. Simplified reaction mechanisms for the oxidation of hydrocarbon fuels in flames. Combust. Sci. Technol. 1981, 27, 31-43.

(2) Jones, W.; Lindstedt, R. Global reaction schemes for hydrocarbon combustion. Combust. Flame 1988, 73, 233-49.

(3) Dally, B. B.; Karpetis, A. N.; Barlow, R. S. Structure of turbulent non-premixed jet flames in a diluted hot coflow. Proc. Combust. Inst. 2002, 29, 1147-1154.

(4) Li, P.; Dally, B. B.; Mi, J.; Wang, F. MILD oxy-combustion of gaseous fuels in a laboratory-scale furnace. Combust. Flame 2013, 160, 933-946.

(5) Shu, Z.; Wang F, Dai C, Si J, Wang B, Mi J. Characteristics of Nitric-Oxide Emissions from Traditional Flame and MILD Combustion Operating in a Laboratory-Scale Furnace. J Therm Sci 2020, 29, 868-883. 